\title{
PEMBERDAYAAN MASYARAKAT MELALUI KOMUNIKASI PENYULUHAN
}

\author{
Mohammad Jibriel Avessina ${ }^{1}$, Septi Amelinda Kustari, Zahra Anisa ${ }^{2}$. \\ avessina@fe.uika-bogor.com \\ Dosen Fakultas Ekonomi ${ }^{1}$, Mahasiswa KKN Kelompok 48 Tahun $2018^{2}$
}

\begin{abstract}
ABSTRAK
Penyuluhan merupakan usaha untuk mengubah pengetahuan, sikap, kebiasaan dan keterampilan dengan membantu, mempengaruhi dan memotivasi masyarakat sehingga dapat meningkatkan taraf hidupnya. Penyuluhan merupakan proses pendidikan diluar sekolah yang diselenggarakan secara sistematis ditujukan pada orang dewasa (masyarakat) agar mau, mampu dan berswadaya dalam memperbaiki atau meningkatkan kesejahteraan keluarganya dan masyarakat luas. Penyuluhan yang dilakukan adalah penyuluhan mengenai kewirausahaan dan hukum dagang. Penyuluhan yang diusung dalam kegiatan ini memiliki tujuan yaitu: (1) Meningkatkan pendapatan masyarakat melalui pelatihan berwirausaha (2) meningkatkan pengetahuan hukum masyarakat melalui penyuluhan hukum dagang. Metode pendekatan yang digunakan dalam kegiatan ini adalah: (1) Pendekatan religius (2) Pendekatan organisasi (3) Pendekatan kekerabatan (4) Pendekatan berdasarkan karakter masyarakat. Setelah kegiatan ini masyarakat Desa Pamijahan khususnya warga Kampung Citamiang 2 lebih mengetahui bagaimana hukum dalam berdagang dan lebih antusias dalam berwirausaha.
\end{abstract}

\section{Kata Kunci : pemberdayaan, penyuluhan, kewirausahaan.}

\section{PENDAHULUAN}

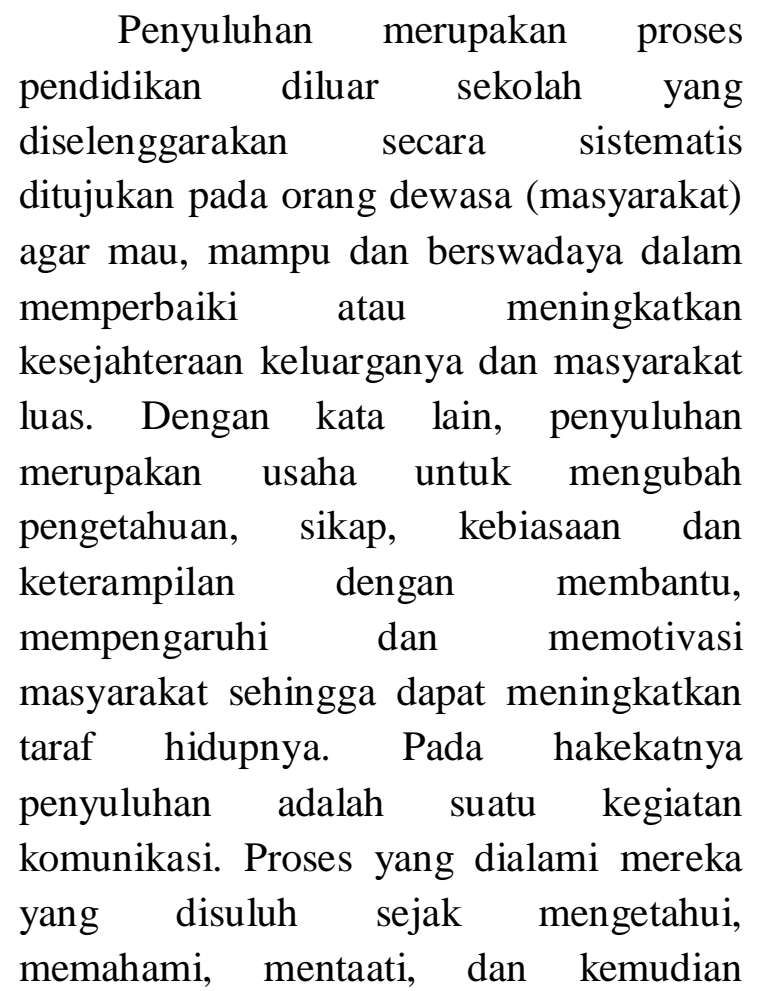

menerapkannya dalam kehidupan yang nyata, adalah suatu proses komunikasi. Komunikasi penyuluhan banyak digunakan oleh lembaga atau instansi baik pemerintah maupun nonpemerintah, untuk menyampaikan dan mempersuasi masyarakat menuju ke arah modernisasi dalam segala bidang atau sektor, yang berdampak langsung pada peningkatan ekonomi mereka secara khusus dan menekan laju pembangunan secara umumnya. Salah satu bidang yang sering dan erat kaitannya dengan penyuluhan adalah bidang kewirausahaan. Sementara pertumbuhan ekonomi suatu masyarakat merupakan poin penting dalam menciptakan kenyamanan dalam kelangsungan hidup masyarakat tersebut.Salah satu desa yang memiliki potensi dalam pembangunan ekonomi 
adalah Desa Pamijahan Kecamatan Pamijahan Kabupaten Bogor. Hal itu karena di desa ini merupakan salah satu desa yang memiliki banyak potensi muatan lokal yang variatif yang dapat menumbuhkan jiwa wirausaha dari tiap warga di Desa Pamijahan.

\section{Keadaan Geografis}

Secara umum luas Desa Pamijahan adalah 396.96 Ha terdiri dari 9 RW dan 31 Rt, Desa Pamijahan memiliki batas di Sebelah Utara berbatasan dengan Desa Situ Udik, sebelah selatan berbatasan dengan Desa Gunung Sari sebela timur berbatasan dengan Desa Pasarean, dan sebelah Barat berbatasan dengan Desa Cibitung Wetan.

\section{Kondisi masyarakat}

Pengabdian kepada masyarakat yang telah dilakukan mengambil tempat di Desa Pamijahan, Kecamatan Pamijahan, Kabupaten Bogor. Desa Pamijahan merupakan sebuah desa mayoritas penduduknya terdiri dari kalangan masyarakat kelas menengah ke bawah dengan sumber penghasilan tidak menentu. Beberapa karakter masyarakat Pamijahan tepatnya di Kampung Citamiang 2 RT 01/ RW 04 berdasarkan observasi dan wawancara yang telah dilakukan adalah sebagai berikut.

1. Hampir $70 \%$ masyarakatnya hanya berpendidikan SD, 20\% SMP dan 10\%
SMA. Sumber Daya Manusia yang rendah ini tentunya sulit untuk berkembang kecuali jika mendapat pendampingan yang terus-menerus dengan metode yang ringkas, padat, dan aplikatif.

2. Banyak remaja yang memilih mencari pekerjaan di kota-kota besar. Fakta ini merupakan sebuah keprihatinan tersendiri karena minimnya lapangan pekerjaan di Kampung Citamiang 2. Dalam penelitian ini, terdapat sejumlah fakta tentang kondisi terakhir masyarakat di Kampung Citamiang 2. Di antaranya masih rendahnya pengetahuan warga mengenai kewirausahaan.

Dari data di atas, dapat disimpulkan bahwa masyarakat di Kampung Citamiang 2 mempunyai dua masalah besar. Pertama adalah kemiskinan dalam pendidikan . Kedua adalah kemiskinan ekonomi. Kemiskinan ini membuat mereka menjadi masyarakat kelas bawah yang tidak bisa berkembang menuju masyarakat mandiri. Profesi petani dan peternak sapi perah dengan daya jual yang rendah kian tidak bisa diandalkan untuk menopang kebutuhan keluarga. Oleh sebab itu, pembinaan kewirausahaan yang dapat menghasilkan pemasukan besar, layak untuk diterapkan kepada mereka dengan didukung oleh berbagi pihak terkait. 


\section{METODE PENGABDIAN}

Tahapan pelaksanaan untuk kegiatan ini sebagaimana terlihat pada bagan sebagai berikut:

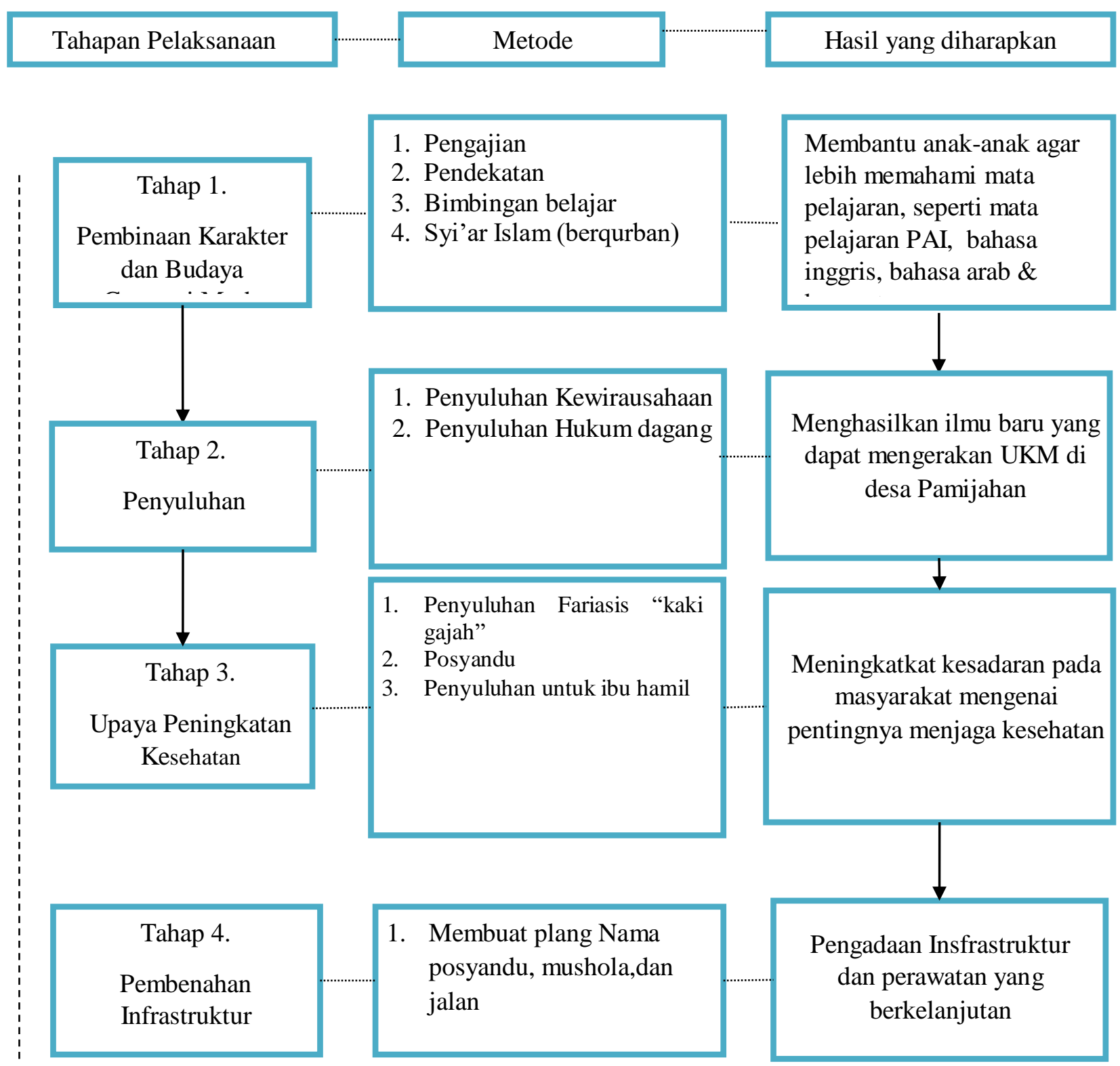




\section{Jadwal Kegiatan}

\begin{tabular}{|c|c|c|c|}
\hline No & Bidang & Jenis kegiatan & Terlaksana \\
\hline \multirow[t]{3}{*}{1} & \multirow[t]{3}{*}{ Pendidikan } & $\begin{array}{l}\text { Mengajar di MI Darul Ulum } \\
\text { Desa pamijahan }\end{array}$ & $\begin{array}{l}\text { Setiap hari Selasa dan } \\
\text { Rabu }\end{array}$ \\
\hline & & $\begin{array}{l}\text { Bimbel Bahasa Inggris, } \\
\text { Bahasa Arab di Posko } 48\end{array}$ & Setiap hari \\
\hline & & $\begin{array}{l}\text { Hafalan kosa kata } \\
\text { (Bahasa Indonesia - Inggris } \\
\text { - Arab) }\end{array}$ & $\begin{array}{l}\text { Setiap Malam Rabu dan } \\
\text { Kamis }\end{array}$ \\
\hline 2 & Hukum & $\begin{array}{l}\text { Penyuluhan tentang hukum } \\
\text { dagang secara umum dan } \\
\text { islami }\end{array}$ & Senin, 20 Agustus 2018 \\
\hline 3 & Ekonomi & $\begin{array}{ll}\text { Seminar } & \text { tentang } \\
\text { Kewirausahaan } & \end{array}$ & Senin, 20 Agustus 2018 \\
\hline \multirow[t]{3}{*}{4} & \multirow[t]{3}{*}{ Teknik } & Bimbingan belajar komputer & Setiap hari Sabtu \\
\hline & & $\begin{array}{l}\text { Pembugaran dan pembuatan } \\
\text { gapura }\end{array}$ & Senin, 13 Agustus 2018 \\
\hline & & $\begin{array}{l}\text { Pembuatan plang jalan, } \\
\text { posyandu dan mushola }\end{array}$ & $\begin{array}{l}\text { Minggu, } 02 \text { September } \\
2018\end{array}$ \\
\hline \multirow[t]{4}{*}{5} & \multirow[t]{4}{*}{ Kesehatan } & Penyuluhan kaki gajah & Selasa, 14 Agustus 2018 \\
\hline & & Puskesmas & Setiap hari Selasa \\
\hline & & $\begin{array}{l}\text { Pemberian vaksin untuk } \\
\text { balita }\end{array}$ & Rabu, 08 Agustus 2018 \\
\hline & & Kelas ibu hamil & Senin, 13 Agustus 2018 \\
\hline \multirow[t]{5}{*}{6} & \multirow[t]{5}{*}{ Agama } & $\begin{array}{lcr}\text { Mengajar } & \text { ngaji di } & \text { rumah } \\
\text { ustad } & \text { Andi } & \text { dan } \\
\text { ustadzMa'ruf } & \end{array}$ & Setiap Hari \\
\hline & & Bimbingan belajar tahsin & Setiap hari \\
\hline & & Pengajian rutinan & $\begin{array}{l}\text { Setiap Rabu malam dan } \\
\text { kamis pagi }\end{array}$ \\
\hline & & Kurban & Rabu, 22 Agustus 2018 \\
\hline & & $\begin{array}{l}\text { Pemasangan media untuk } \\
\text { mengaji di rumah ustadz dan } \\
\text { penyerahan bantuan untuk } \\
\text { pengajian anak-anak }\end{array}$ & Selasa, 04 September 2018 \\
\hline
\end{tabular}




\section{Metode Pendekatan}

Pendekatan yang digunakan dalam kegiatan KKN ini yaitu dengan pendekatan sosial. Pendekatan sosial merupakan hal yang amat penting untuk dilakukan guna menunjang keberhasilan KKN. Oleh karena itu, penyelenggaraan $\mathrm{KKN}$ perlu didasari oleh pendekatan sosial yang tepat dan memadai, baik pada saat perencanaan, pelaksanaan, maupun pada tahap evaluasi.

Pendekatan sosial dilakukan melalui tahapan-tahapan yang sistematis, meliputi tahapan:

\section{- Pembukaan Hubungan}

Dalam tahapan ini mahasiswa beserta dosen pembimbing dapat mengadakan diskusi atau lokakarya dengan semua pihak strategis di masyarakat tentang rencana kerja.

\section{- Pemeliharaan Hubungan}

Hubungan yang telah terjalin melalui tahapan sebelumnya, selanjutnya perlu dipelihara dan dijaga agar suasana KKN tetap berjalan kondusif.Kehangatan dan keakraban serta saling percaya dengan masyarakat terus dipelihara melalui kegiatan komunikasi secara formal maupun informal.Dalam pemeliharaan hubungan, komunikasi informal dapat memberikan hasil yang jauh lebih efektif.

\section{- Pembinaan Hubungan}

Pembinaan hubungan terutama dilaksanakan oleh pengelola KKN (lembaga atau tim yang ditunjuk oleh perguruan tinggi yang bersangkutan) pada saat mengadakan pemantauan (monitoring) dan evaluasi terhadap rencana dan pelaksanaan kegiatan yang telah disetujui pihak-pihak strategis. Pada tahap ini dapat terjalin hubungan kerja sama antara Perguruan Tinggi dengan masyarakat yang tidak hanya sebatas $\mathrm{KKN}$, akan tetapi sangat dimungkinkan pula untuk menjalin kerja sama lanjutan yang mutualisme, setelah masa KKN berakhir.

- Mengakhiri Hubungan

Pada tahap ini peserta KKN berpamitan dengan masyarakat, baik secara formal maupun personal.Secara formal biasanya dilakukan secara seremonial dalam bentuk acara khusus pelepasan peserta KKN oleh masyarakat setempat.

\section{Partisipasi Masyarakat dalam Pelaksanaan Program}

Partisipasi masyarakat yang dapat dilakukan dalam kegiatan ini adalah sebagai berikut:

1) Menyediakan tempat tinggal bagi peserta KKN

2) Mempersiapkan tempat untuk pembinaan dan pelatihan.

3) Mempersiapkan warga yang bersedia mengikuti pembinaan dalam kegiatan penyuluhan

4) Pelaksanaan pengajian rutinan Warga (Bulanan/Mingguan) bersama peserta KKN.

\section{Langkah Evaluasi}

Evaluasi yang dilakukan terdiri dari :

a. Evaluasi proses, yang terkait dengan perencanaan, pelaksanaan, dan monitoring kegiatan. Evaluasi proses dilakukan setiap pekan bersama pejabat dan tokoh masyarakat.

b. Evaluasi hasil, yang dilaksanakan setelah kegiatan dilaksanakan. Evaluasi hasil ditujukan guna meningkatkan kesadaran tentang pentingnya berwirausaha, kesehatan,dan pendidikan kepada warga. 


\section{REALISASI PROGRAM}

Realiasasi Program Mahasiswa KKN dilaksanakan selama kurang lebih 30 hari terhitung sejak tanggal 7 Agustus 2018 sampai dengan 5 September 2018. Berikut ini adalah laporan berbagai kegiatan yang telah dilaksanakan oleh mahasiswa KKN di Desa Pamijahan, Kecamatan Pamijahan, Kabupaten Bogor yang dilaksanakan oleh enam divisi yaitu: Divisi Pendidikan, Divisi Kesehatan Masyarakat, Divisi Ekonomi, Divisi Teknik, Divisi Agama, daan divisi hukum dengan total jumlah 7 program kerja terlaksana.

\section{Bidang Pendidikan}

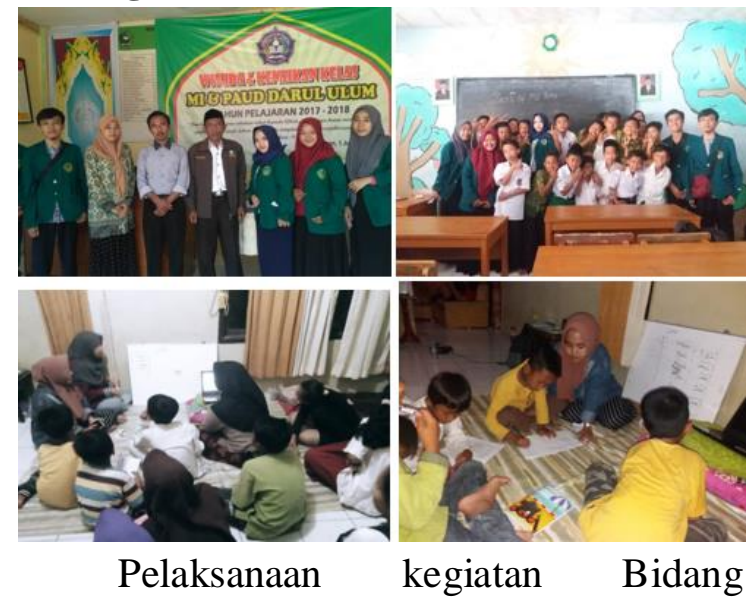

Pendidikan dari masing-masing mahasiswa KKN 48 mendapatkan respon yang positif dari masyarakat sekitar. Dengan adanya kegiatan pendidikan dari mahasiswa $\mathrm{KKN}$ 48 Universitas Ibn Khaldun warga merasa mendapatkan wawasan baru baik dari segi kesehatan, teknologi, ekonomi, dan pemberdayaan lingkungan. Namun, kendala di dalam pelaksanaan kegiatan dibidang pendidikan ini adalah waktu dari warganya serta kemauan belajar dari warga serta anak-anak dikampung Citamiang 2 yang masih kurang. Kendala lain adalah kurangnya tenaga pengajar, maka kami mahasiswa KKN 48 yang harus terjun langsung ke sana, yang kami lakukan dalam 1 minggu 2 kali. Kami juga memberikan bimbingan belajar bahasa Inggris dan bahasa Arab di Posko dengan tujuan anak-anak dapat memahami bahasa asing.

\section{Bidang Kesehatan}

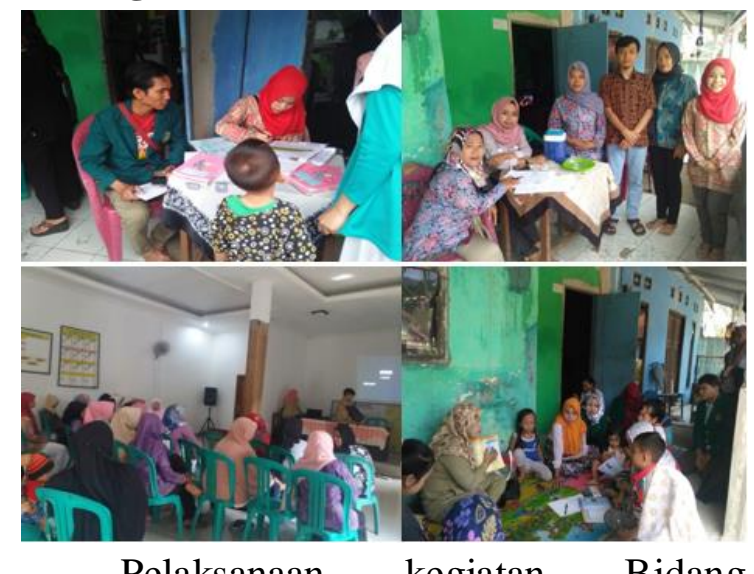

Pelaksanaan

kegiatan

Bidang

Kesehatan dari masing-masing mahasiswa KKN 48 mendapatkan respon yang positif dari masyarakat sekitar. Dengan adanya kegiatan kesehatan dari mahasiswa KKN 48 Universitas Ibn Khaldun warga merasa senang ketika kami melakukan penyuluhan mengenai bahaya kaki gajah dan cara pencegahannya. Dengan bekerja sama dengan lembaga kesehatan seperti pukesmas dan posyandu, mahasiswa KKN 48 memberikan penyuluhan dan pemberian imunisasi bagi balita dan kelas bagi ibu hamil.

\section{Bidang Ekonomi}

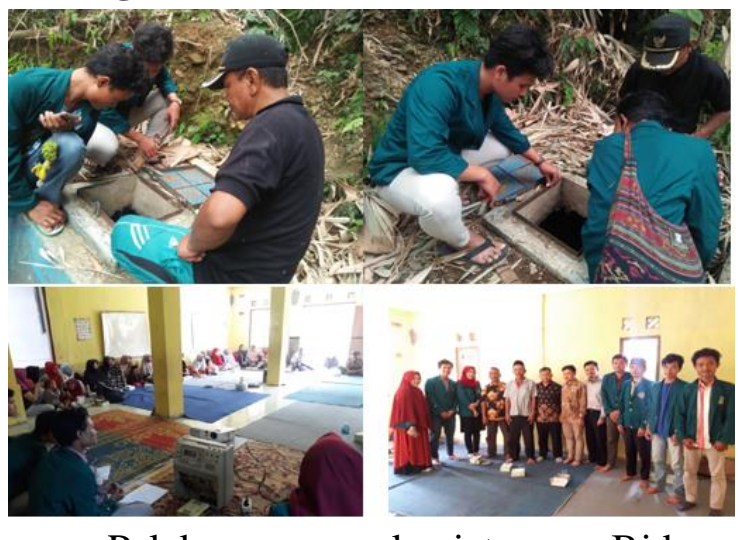

Pelaksanaan

kegiatan

Bidang

Ekonomi dari masing-masing mahasiswa 
KKN 48 Universitas Ibn Khaldun mendapatkan respon yang positif dari masyarakat sekitar. Mahasiswa membuat suatu seminar kewirausahaan dengan tema "Pentingnya Berwirausaha secara umum dan islami" dengan fokus utama kami agar bagaimana masyarakat desa pamijahan tidak hanya menjual hasil pertanian dan peternakan kepada pengepul tapi juga bisa mengolah dan berwirausaha secara mandiri dengan aturan yang benar. Selain itu Desa Pamijahan juga merupakan salah satu Desa yang memiliki BUMDES yang berfokus pada pengadaan sumber air bersih bagi warga sehingga mahasiswa KKN 48 tertarik untuk mempelajari bagaimana cara kerja dan pengelolaan BUMDES namun terhenti karena adanya konflik yang tidak bisa diketahui oleh umum.

\section{Bidang Hukum}

Pelaksanaan kegiatan Bidang Hukum dari mahasiswa KKN 48 Universitas Ibn Khaldun mendapatkan respon yang positif dari masyarakat sekitar, pada saat survey banyak warga yang belum mengetahui bagaimana hukum dalam berdagang, bagaimana cara mendirikan $\mathrm{CV}$, mendirikan usaha sendiriatau perkelompok seperti UKM(usaha kecil menengah). sehingga mahasiswa KKN 48 membuat penyuluhan mengenai hukum dagang yang sinkron dengan penyuluhan kewirausahaan.
Bidang Agama
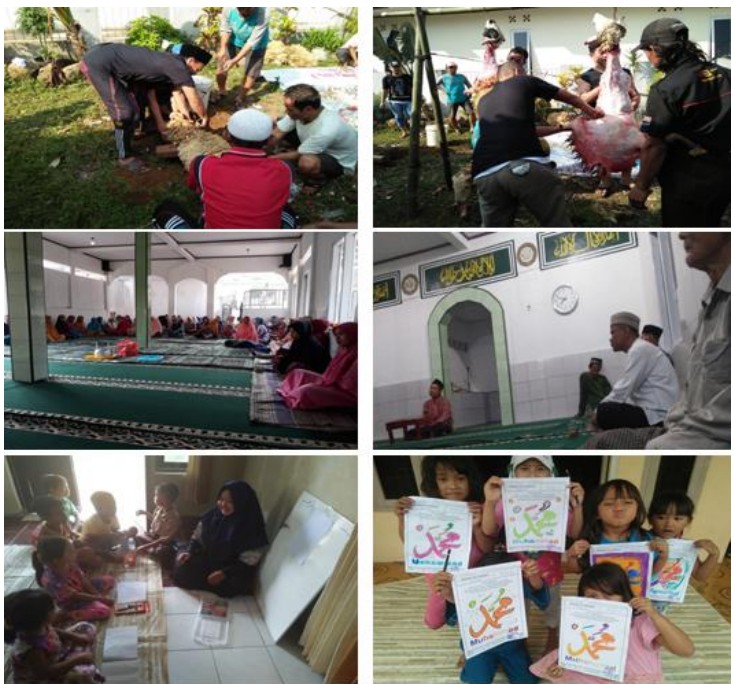

Pelaksanaan kegiatan Bidang Agama dari mahasiswa KKN 48 Universitas Ibn Khaldun mendapatkan respon yang positif dari masyarakat sekitar. Mengajar mengaji di rumah ustad Andi dan ustadz Ma'ruf adalah bentuk kepedulian mahasiswa untuk membantu ustadz di Kampung citamiang 2. Selain itu mahasiswa juga mendirikan sebuah tempat bimbingan belajar di posko yaitu "taman beriman dan berbudaya" yang mengajarkan mengenai ilmu tahsin dan tajwid. Selain itu juga mahasiswa KKN 48 mengikuti pengajian mingguan selama berada di posko KKN 48, dan merayakan hari raya idul adha di kampung citamiang 2 dan memberikan satu ekor kambing untuk berkurban. 


\section{Bidang Teknik}

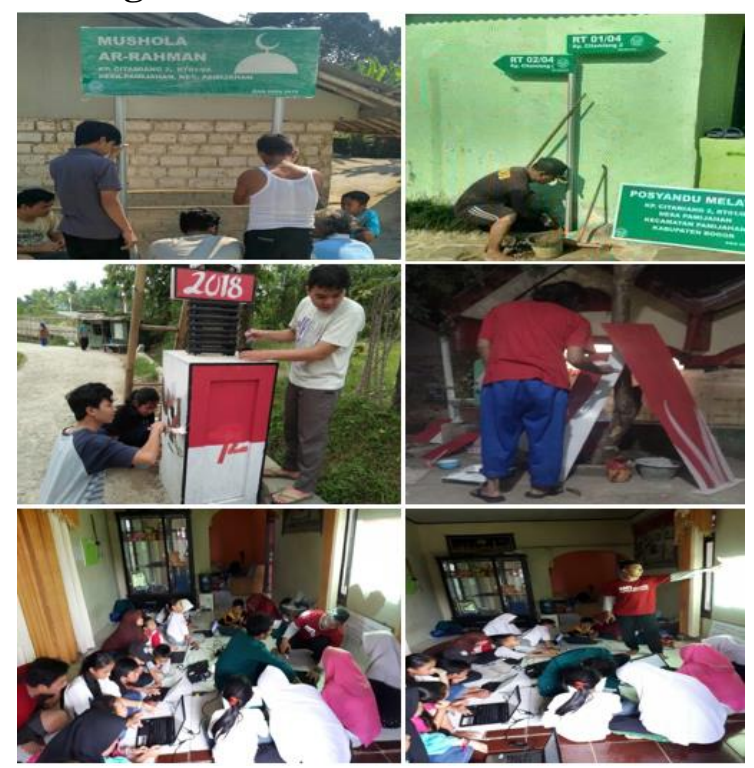

Pelaksanaan kegiatan Bidang Teknik dari mahasiswa KKN 48 Universitas Ibn Khaldun mendapatkan respon yang positif dari masyarakat sekitar. Teknologi adalah hal terpenting dizaman modern saat ini, mahasiswa dengan kepeduliannya membuat kegiatan bimbingan belajar komputer untuk kalangan anak-anak sampai remaja. Mahasiswa juga memlakukan pembugaran insprastruktur, seperti membuat gapura, pembugaran gapura yang sudah ada, membuat plang untuk jalan, plang untuk posyandu dan mushola.

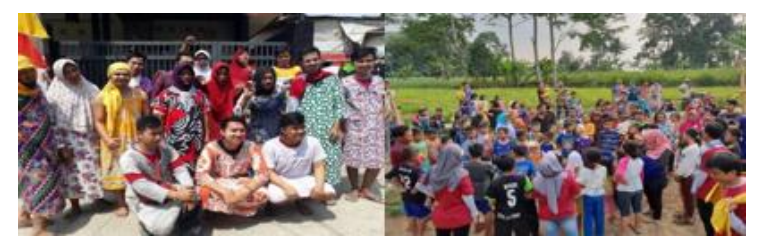

\section{HUT RI ke 73}

Dengan tujuan agar generasi penerus bangsa dapat mengohormati jasa-jasa para pahlawan, dapat mengamalkan nilai-nilai baik dari perjuangan para pahlawan, dan dapat meningkatkan kecintaan terhadap NKRI.

\section{KESIMPULAN}

Kuliah Kerja Nyata merupakan sarana bagi mahasiswa untuk menyalurkan potensinya sebagai agen perubahan. Peran mahasiswa yang mampu melakukan berbagai aksi untuk menjadi bagian dari agen perubahan (agent of change) yang signifikan terhadap desa yang dijadikan sebagai objek KKN. Karenanya KKN dijadikan program rutin hampir sebagian besar kampus-kampus di Indonesia dan dijadikan sebagai syarat kelulusan untuk mahasiswa. Termasuk di Universitas Ibn Khaldun Bogor yang juga mengadakan program KKN yang terbagi dalam beberapa kelompok. Salah satunya kelompok 48 yang bertempat di Kecamatan Pamijahan.

Berikut beberapa kesimpulan yang dapat kami jabarkan selama program KKN kelompok 48 yang berlangsung kurang lebih selama 30 hari di Desa Pamijahan Kecamatan Pamijahan :

1. Terealisasinya program pengabdian kepada masyarakat yang dilakukan oleh mahasiswa dalam rangka mewujudkan program Universitas Ibn Khaldun Bogor sesuai dengan Visi dan Misi Universitas Ibn KhaldunBogor.

2. Terbentuknya karakter building para mahasiswa dan mahasiswi yang mengikuti program KKN ini.

3. Terbentuknya program kerjasama langsung antara mahasiswa dan masyarakat yang bisa saling bersinergi dan saling menguntungkan.

4. Meningkatkan kepedulian dan rasa empati mahasiswa kepada permasalahan masyarakat, sehingga terjadinya perubahan perilaku mahasiswa kepada masyarakat. 
Selain itu, KKN yang dilaksanakan oleh kelompok 48 juga memberikan dampak yang signifikan bagi masyarakat. Dampak bagi masyarakat diantaranya terbantukannya sekolah-sekolah yang kekuarangan guru, terbentuknya masyarakat yang lebih berjiwa enterpreneur, meningkatnya kesadaran masyarakat terhadap pentingnya pendidikan agama, ilmu teknologi, dan bahasa asing seperti bahasa arab dan inggris, meningkatnya kesadaran masyarakat terhadap pentingnya menjaga kesehatan, dan terbantukannya masyarakat dengan adanya pembuatan dan pembugaran insprastruktur seperti plang dan gapura.

Diharapkan masyarakat dapat melanjutkan program-program yang telah dilaksanakan oleh mahasiswa KKN Universitas Ibn Khaldun Bogor dan dapat meningkatkan kerjasama lintas sektor. Masyarakat dan pihak desa aktif bekerja sama dalam mengembangkan program kerja desa yang sudah ada dibuat oleh desa, dengan masukan di adakannya program untuk generasi muda - remaja yang diharapkan akan menjadi penentu kemajuan desa dikemudian hari. Adanya kontrol kerja desa dengan teknologi yang sudah berkembang, seperti rencana program desa, program yang sudah terlaksana, program yang selesai di bangun, jumlah kependudukan, kepengurusan desa agar program desa dapat terlaksana dan terkontrol lebih baik.

\section{REFERENSI}

Dewi, Yuni Retna. 2006. Teknik Komunikasi Pada Proses Pendekatan Masyarakat (Makalah). Jakarta: LPM Universitas Trisakti.

Daryanto, 2014. Perubahan pendidikan dalam masyarakat social budaya, Jakarta : Satu nusa.

https://penduaismine.wordpress.com/2013/ 04/30/penyuluhan-sebagai-suatuaktivitas sosial-pembangunan/

Subagyo, P. J. (2011). Metodologi

Penelitian Dalam Teori dan Praktek . Jakarta: Aneka Cipta.

Suyono, H., \& Haryanto, R. (2009). PEDOMAN PELAKSANAAN KKN POS PEMBERDAYAAN KELUARGA (POSDAYA). Depok: CITRA KHARISMA BUNDA.

Suhandi, Agraha. 1993. Pola Hidup Masyarakat Indonesia. Bandung: Fakultas Sastra Universitas Padjajaran 